\title{
Welfare to Work Propensities: Administrative Record Evidence
}

Ting Zhang, University of Baltimore

Department of Finance and Economics

University of Baltimore

410-836-6551

tzhang@ubalt.edu

Dan Gerlowski, University of Baltimore

Department of Finance and Economics

University of Baltimore

410-837-4987

dgerlowski@ubalt.edu

\begin{abstract}
The study examines the role of home-to-new-job-hub distance on employment propensity using a unique dataset compiled from integrated micro-level administrative records of work-eligible welfare recipients and earnings. Our empirical findings confirm the Spatial Mismatch Hypothesis. Our home-to-new-job-hub distance measure is an innovative weighted measure incorporating both abundance of actual employment opportunities and geographic distance. Other unique contributions of this study include using point-to-point residence and job hub locational information, modeling with community controls, and industry specific analysis. This study also identifies policy implications in advancing employment prospects of inner-city residents receiving government assistance.
\end{abstract}

\section{Acknowledgement}

The study relied on data from Family Investment Administration, the state Department of Human Resources \& Office of Workforce Information and Performance, the state Department of Labor, Licensing and Regulation. We deeply appreciate the important support from those two agencies. In addition, we feel deeply indebted to David Stevens and Regina Bento's advice and a couple of Jacob France Institute staff members' research support. The author accepts full and sole responsibility for the content of this study. Agreement or disagreement with the views expressed here should not be attributed to any other person or organization.

Keywords: job access, spatial mismatch, welfare to work, I38, R49, J49. 


\section{Welfare to Work Propensities: Administrative Record Evidence}

\subsection{Introduction}

The February 2008 Reauthorization of the Temporary Assistance for Needy Families (TANF) Final Rule included a personal responsibility charge for work-eligible recipients encouraging their return to the labor force. This study explores the employment propensity of TANF recipients in a large US City in the backdrop of the Spatial Mismatch Hypothesis (SMH) of Kain (1968). We also analyze other socio-economic factors associated with home-to-new-job-hub distance. It is based on point-to-point distances and a unique measure of job opportunities. Both individual and community factors are investigated allowing for community effects, and we analyze employment propensity by industry. The problem of endogeneity between job and housing choices identified by Ihlanfeldt and Sjoquist (1998) is partially controlled by our population choice which contains lower income individuals in a post-recession period as done in Andersson et al (2015) and by controlling for local economic conditions.

\subsection{Research Hypotheses} hypotheses:

Building on the SMH literature and other previous studies, we test the following two

H1: Distances between home and potential job opportunities (i.e., home-to-new-job-hub distances) negatively impact TANF recipients' employment propensity.

H2: Controlling for demographics and local economic conditions, TANF recipients' child care responsibility, lower education attainment, poorer health, and living in the poorer community are associated with lower odds of finding a job.

\subsection{Methodology}

This study tracks work-eligible TANF recipients' employment propensity for up to four quarters after receiving cash assistance. We define work-eligible TANF recipients as individuals aged 19-69 that received cash assistance in any month or combination of post-recession months between July 2009 and December 2011. Our employment records therefore track up to December 2012.

In order to better use the longitudinally linked administrative records, we extracted data from the state Client Automated Resources and Eligibility System and the Quarterly Census of Employment and Wages ${ }^{1}$. We integrated multiple longitudinal administrative datasets to obtain point specific location information for both individuals and job opportunities. A validation

\footnotetext{
${ }^{1}$ Those data were extracted under inter-agency agreement, subject to strict security and confidentiality clauses.
} 
process, using address probabilistic matching, based on personal identification numbers eliminated $23 \%$ of our potential observations leaving 24,211 records. $^{2}$

\subsection{Distance Measure to Job Opportunities}

We identify the locations of new job hubs that generated at least 100 new jobs in each month. The distance between TANF recipients' homes and those top new job hubs, $\mathrm{d}_{\mathrm{ij}}$, is calculated using the Haversine Formula ${ }^{3}$ and weighted by the ranking of that new job hub location, $\mathrm{p}_{\mathrm{ij}}$. The ranking factor includes the top 10 new job hubs each month and reflects a gravity modeling rationale, the farthest job hub among the top 10 hubs from home receives the lowest ranking of 1 .

$$
\mathrm{HNJHD}=\sqrt{\sum d_{i j}^{2} * p_{i j}}
$$

There are several advantages of HNJHD over similar measures appearing in the literature(e.g., Bania et al, 2008, Åslund and Skans, 2010, or Ihlanfeldt and Sjoquist, 1998). By including the number of actual area jobs, it incorporates both labor market supply and demand impacts; it is based on actual point-to-point distances rather than on aggregated geographic areas; it measures access to potential job opportunity, instead of commuting distance.

\subsection{Model and Variables}

We adopt a robust fixed-effect linear probability model to test the impact of HNJHD on TANF recipients' employment propensity, controlling for individual and community attributes.

$$
\begin{array}{r}
\operatorname{Probability}\left(\mathrm{Y}=1 \mid \mathrm{HNJHD}, X_{1}, \ldots, X_{n}\right)=\mathrm{E}\left[\mathrm{Y} \mid \mathrm{HNJHD}, X_{1}, \ldots, X_{n}\right] \\
=\mathrm{a}+\lambda \mathrm{HNJHD}+\beta_{1} X_{1}+\cdots+\beta_{n} X_{n}
\end{array}
$$

In addition to HNJHD, individual socio-economic and demographic influences, and community factors are considered. Age, gender, race and ethnicity, marital status, education attainment, a health proxy, and an indicator of the responsibility for young children capture individual characteristics. The local area fixed effects are at the Census Community Statistical Area (CSA) level and capture poverty environment (\% of local families in TANF) and community population to employment ratios.

\footnotetext{
2 They consist of 18,528 individuals across different communities.

${ }^{3}$ This gives great-circle distances(d) between two points (O and D) on a sphere (i.e., the earth in this case) from their longitudes and latitudes $(\mathrm{Y}$ and $\mathrm{X})$ using the radius of the earth at Washington $\mathrm{DC}, \mathrm{d}=2 * \mathrm{r}$$$
* \arcsin \left(\sqrt{\sin ^{2}\left(\frac{X_{D_{i j}}-X_{O_{i j}}}{2}\right)+\cos \left(X_{D_{i j}}\right) \cos \left(X_{O_{i j}}\right) \sin ^{2}\left(\frac{Y_{D_{i j}}-Y_{O_{i j}}}{2}\right)}\right. \text {. }
$$ 
We use linear probability models because we estimate the averaged partial effects of covariates on the response probability (Wooldridge, 2002). The model is fixed at the local community level allowing for arbitrary correlations (Pohlman and Leitner, 2003; Angrist and Pischke, 2009) and adopt robust standard errors to address potential heteroscedasticity issues.

\subsection{Findings}

Table 1 shows a snapshot of the work-eligible TANF recipients. A majority are female (91\%), black (92\%), and not married (95\%). In addition, $21 \%$ of the work-eligible TANF recipients reported some disability and $23 \%$ have responsibility for a child under 1 year.

<Table 1 placed about here>

The employment by industry distribution at the 2 digit North American Industry Classification System (NAICS) level is not uniform. Of the $54 \%$ of our sample reporting an industry affiliation, $76 \%$ were in four industries: Retail Trade $(23 \%)$, Administrative Services (19\%), Health Services (18\%), and Accommodations (15\%). The by-industry analysis focuses on these four industries.

Our fixed effect linear probability model results for the overall impact, as well as impacts by major industry sectors are presented in Table 2

$<$ Table 2 placed about here>

Our results find strong confirmation overall of the SMH with some industry variation. Clearly distance from home to emergent new job hubs (i.e. home-to-new-job-hub distance, or HNJHD) negatively impacts employment prospects confirming the SMH, except for jobs obtained in Retail Trade. Retail Trade jobs are typically residential based and located within communities, potentially minimizing the distance factor.

TANF recipients with young children have lower job placement propensities. This is consistent with our expectation and findings in Blumenburg and Ong (2001): the impacts of some socio-economic barriers may be magnified by distance. This effect is pronounced except for Retail Trade and Accommodation, both of which typically have hour-based shifts which may allow for more flexible scheduling accommodating child responsibilities.

Lower education attainment results in lower odds of obtaining a job, consistent with Cheng et al (2016), but not for some industries. The presence of a college degree does not necessarily impact employment propensity, due in part to approximately $1 \%$ of the sample having a college degree. 
Disability, older age and being male tend to associate with lower job placement odds overall and across industries.

Race and ethnicity also impact ultimate employment odds. Asian or Pacific Islanders, as a group, are strong contenders for jobs with noted exceptions in Retail Trade and Health Services, perhaps indicating communication barriers. African Americans, as a group, fare well in job seeking in all industries, with the exception of Retail Trade.

Community effects are also significant. A resident from a poorer community has significantly lower odds of finding a job. However, the population to employment ratio proved insignificant in all formulations but was retained due its role as a control variable in the fixedeffects approach and also to minimize potential endogeneity.

\subsection{Conclusion}

Our empirical analysis confirmed the SMH with individual and community level details and identified additional roles played by child care responsibility, lower education attainment, poor health, and residing in a poorer community. The longitudinal data set used is compiled by integrating administrative records with point to point spatial measures. We explicitly designed a comprehensive home-to-new-job-hub distance measure reflecting not only distance to job opportunities but quantity of new job created. Our results call for policy attention to better physically connect TANF recipients to jobs, with particular attention to childcare, health, and educational attainment. Future research may be directed at including travel or commuting time instead of distance and extend the analysis to an urban versus suburban or rural framework. The industry-specific analysis calls for more nuance in human resource and workforce development needs of individual industries relative to the individual qualifications of nearby, accessible jobseekers.

\section{References}

Andersson, F., J. C. Haltiwanger, M. J. Kutzbach, H. O. Pollakowski, and D. Weinberg. 2014. "Job Displacement and the Duration of Joblessness: The Role of Spatial Mismatch." NBER Working Paper 20066, www.nber.org/papers/w20066.

Angrist, J. D. and Pischke, J. (2009). Mostly Harmless Econometrics. Princeton, NJ: Princeton University Press.

Åslund, O., \& Skans, O. N. (2010). Will I see you at work? Ethnic workplace segregation in Sweden, 1985-2002. Industrial \& labor relations review, 63(3), 471-493.

Bania, N., L. Leete, and C. Coulton. 2008. "Job Access, Employment and Earnings: Outcomes for Welfare Leavers in a US Urban Labour Market." Urban Studies 45: 2179-2202.

Blumenberg, E. and P. Ong. 2001. "Cars, Buses, and Jobs: Welfare Recipients and Employment Access in Los Angeles." Journal of the Transportation Research Board, 1756: 22-31. 
Cheng, T., Lo, C., \& Weber, J. 2016. Racial Disparities in Welfare Dependence and Financial Independence: Links to Human Capital, Local Economy, and State Temporary Assistance for Needy Families Policies. Journal of Social Service Research, 1-16

Ihlanfeldt, K.R. and D. Sjoquist. 1998. "The spatial mismatch hypothesis: A review of recent studies and their implications for welfare reform." Housing Policy Debate 9(4): 849-892

Kain, J. 1968. "Housing Segregation, Negro Employment, and Metropolitan Decentralization." Quarterly Journal of Economics 82: 175-197.

Pohlman, J. T.and Leitner, D. W. (2003) . "A Comparison of Ordinary Least Squares and Logistic Regression.” The Ohio Journal of Science. v103, n5 (December, 2003), 118125.

Wooldridge, J. M. 2010. Econometric Analysis of Cross Section and Panel Data. Cambridge, MA: The MIT Press. 
Tables to Be Inserted In the Text

\section{Table 1. Summary of Work Eligible TANF Recipients}

\begin{tabular}{|l|r|r|}
\hline Variable & Mean & Std. Dev. \\
\hline Individual Characteristics & & \\
\hline Worked within 3-12 months after TANF started & 0.25 & 0.43 \\
\hline Distance from Home to Job Hubs (HNJHD) & 6.07 & 1.13 \\
\hline Age & 29.77 & 8.83 \\
\hline Male & 0.09 & 0.28 \\
\hline Married & 0.05 & 0.21 \\
\hline Race: Asian Pacific & 0.01 & 0.09 \\
\hline Race: Black & 0.92 & 0.28 \\
\hline Ethnicity: Hispanic & 0.01 & 0.07 \\
\hline Education: High School & 0.39 & 0.49 \\
\hline Education: College + & 0.01 & 0.10 \\
\hline With Disability & 0.21 & 0.41 \\
\hline With Children under 1 Year Old & 0.23 & 0.42 \\
\hline Neighborhood Characteristics & & \\
\hline Percent of Families Receiving TANF & 14.41 & 6.83 \\
\hline Population Employment Ratio & 6.26 & 3.62 \\
\hline Note: The minimum and maximum HNJHD are 1.03 and 14.55 respectively. & The Percent of \\
\hline Families Receiving TANF ranged from 0.3 to 27.6 and the Population Employment Ratio & \\
\hline ranged from 0.07 to 20.79 across communities. & & \\
\hline
\end{tabular}

Table 2. Fixed-effects (within) regression Results

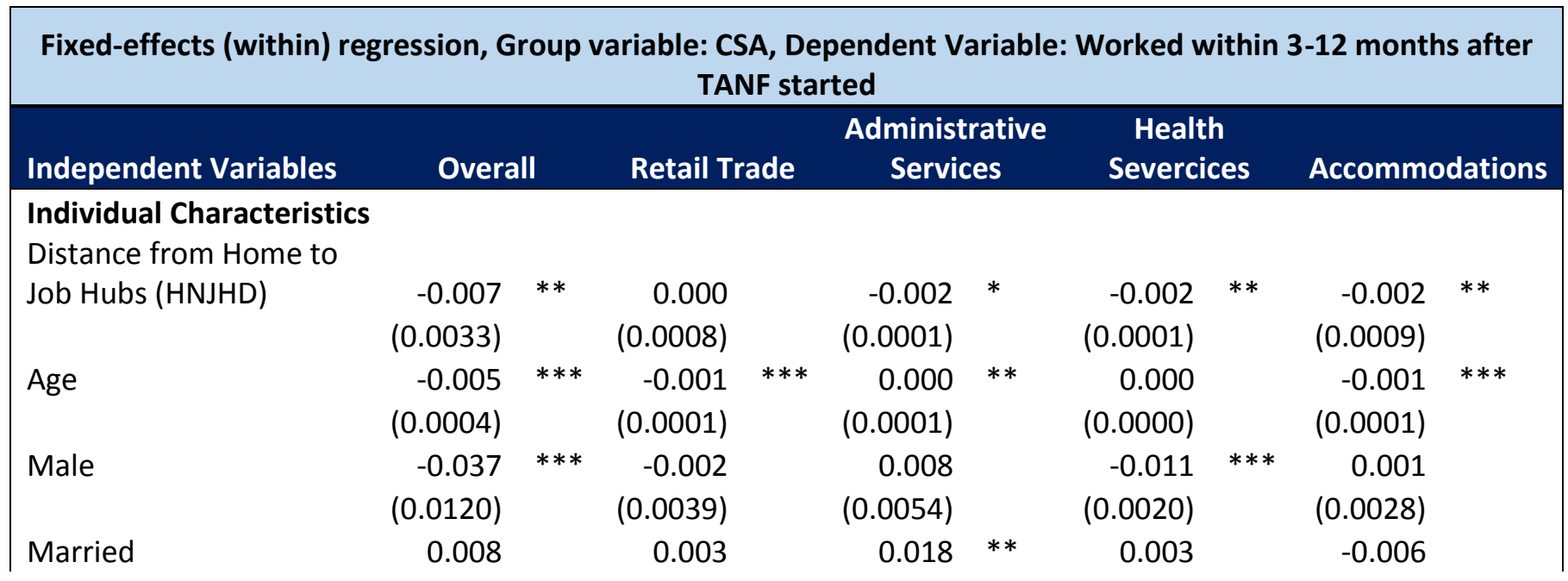




\begin{tabular}{|c|c|c|c|c|c|c|c|c|c|c|}
\hline \multirow{3}{*}{ Race: Asian Pacific } & $(0.0132)$ & & $(0.0044)$ & & (0.0069) & & $(0.0043)$ & & $(0.0040)$ & \\
\hline & 0.199 & $* * *$ & -0.021 & $* * *$ & 0.157 & $* * *$ & -0.012 & $* * *$ & -0.003 & \\
\hline & $(0.0209)$ & & $(0.0056)$ & & $(0.0133)$ & & $(0.0039)$ & & $(0.0041)$ & \\
\hline \multirow[t]{2}{*}{ Race: Black } & 0.036 & $* * *$ & -0.004 & & 0.020 & $* * *$ & 0.006 & $* *$ & 0.006 & $* *$ \\
\hline & $(0.0126)$ & & $(0.0039)$ & & (0.0029) & & $(0.0025)$ & & $(0.0029)$ & \\
\hline \multirow[t]{2}{*}{ Ethnicity: Hispanic } & -0.049 & & -0.008 & & 0.010 & & 0.002 & & 0.008 & \\
\hline & $(0.0354)$ & & $(0.0136)$ & & (0.0128) & & $(0.0082)$ & & $(0.0104)$ & \\
\hline \multirow[t]{2}{*}{ Education: High School } & -0.025 & $* * *$ & 0.002 & & -0.002 & & 0.002 & & -0.011 & $* * *$ \\
\hline & $(0.0050)$ & & $(0.0026)$ & & $(0.0021)$ & & $(0.0015)$ & & $(0.0019)$ & \\
\hline \multirow[t]{2}{*}{ Education: College + } & 0.013 & & -0.009 & & 0.031 & & 0.016 & & 0.004 & \\
\hline & $(0.0250)$ & & $(0.0076)$ & & (0.0185) & & $(0.0098)$ & & $(0.0102)$ & \\
\hline \multirow[t]{2}{*}{ With Disability } & -0.040 & $* * *$ & -0.007 & $* * *$ & -0.010 & $* * *$ & -0.007 & $* * *$ & -0.003 & \\
\hline & $(0.0056)$ & & $(0.0020)$ & & $(0.0022)$ & & $(0.0020)$ & & $(0.0027)$ & \\
\hline \multicolumn{11}{|l|}{ With Children under 1} \\
\hline \multirow[t]{2}{*}{ Year Old } & -0.025 & $* * *$ & -0.003 & & -0.011 & $* * *$ & -0.006 & $* *$ & -0.002 & \\
\hline & $(0.0079)$ & & $(0.0028)$ & & $(0.0024)$ & & $(0.0024)$ & & $(0.0020)$ & \\
\hline \multicolumn{11}{|c|}{ Neighborhood Characteristics } \\
\hline Receiving TANF & $\begin{array}{r}-0.031 \\
(0.0038)\end{array}$ & $* * *$ & $\begin{array}{r}0.000 \\
(0.0010)\end{array}$ & & $\begin{array}{r}-0.002 \\
(0.0011)\end{array}$ & $*$ & $\begin{array}{r}-0.004 \\
(0.0010)\end{array}$ & $* * *$ & $\begin{array}{r}-0.002 \\
(0.0007)\end{array}$ & $* *$ \\
\hline \multicolumn{11}{|l|}{ Population Employment } \\
\hline \multirow[t]{2}{*}{ Ratio } & -0.015 & & -0.004 & $*$ & 0.001 & & -0.003 & & 0.001 & \\
\hline & $(0.0110)$ & & $(0.0024)$ & & $(0.0020)$ & & $(0.0025)$ & & $(0.0015)$ & \\
\hline \multirow[t]{2}{*}{ Constant } & 0.979 & $* * *$ & 0.094 & $* * *$ & 0.056 & $* * *$ & 0.109 & $* * *$ & 0.080 & $* * *$ \\
\hline & $(0.0573)$ & & $(0.0158)$ & & (0.0184) & & $(0.0172)$ & & $(0.0136)$ & \\
\hline \multirow{3}{*}{$\begin{aligned} \text { R-sq: } & \text { within } \\
& \text { between } \\
& \text { overall }\end{aligned}$} & 0.025 & & 0.006 & & 0.010 & & 0.004 & & 0.005 & \\
\hline & 0.130 & & 0.002 & & 0.024 & & 0.000 & & 0.124 & \\
\hline & 0.002 & & 0.002 & & 0.007 & & 0.001 & & 0.002 & \\
\hline F statistics & 53 & $* * *$ & 112 & $* * *$ & 24 & $* * *$ & 25 & $* * *$ & 15 & $* * *$ \\
\hline Number of Observation & 24211 & & 24211 & & 24211 & & 24211 & & 24211 & \\
\hline Number of Groups & 55 & & 55 & & 55 & & 55 & & 55 & \\
\hline
\end{tabular}

